\title{
Antipsychotics in major neurocognitive disorders: controversies for reflections
}

\section{Opinion}

The risks and benefits of the use of antipsychotics in the treatment of cognitive, perceptomotor and social cognitive disorders, characteristics of the major neurocognitive disorder, has been a controversial discussion in the academic environment and, therefore, still far from a uniformity capable of beaconing the medical conduct when this is the therapeutic option for the reduction of the behavioral and psychological symptoms of the demential processes (SCPD).

Perhaps one aspect worth exploring again is the one that correlates the risk of the presence of SCPD, which, on the one hand, is associated with a possible unfavorable outcome due to the increased risk of death in patients ${ }^{1}$ and on the other, that the presence of SCPD has been shown to be one of the main factors for the increase of stress among caregivers of patients with dementia, which consequently affects a higher prevalence of psychiatric disorders (from burnout to depressive disorders) in this population. ${ }^{2,3}$

Forenza \& $\mathrm{Cretaz}^{4}$ in summarizing the main aspects of the behavioral syndromes in dementias, emphasize that, in general, including Alzheimer's disease, the prevalence of delusional ideation varies between $15.7 \%$ and $43.5 \%$, with the most frequent delusions of paranoid content ranging from suspicions and unstructured suspicions to ideas of being robbed or beliefs about the presence of strangers in the house. Delusions of abandonment, grandeur, infidelity, and delusional delusions are also described. Other pictures found less commonly, but with great psychopathological richness, are the Capgras syndrome and reduplicative paramnesia.

Without any oversight, authors such as Sultzer ${ }^{5}$ emphasize that the alterations in the perception of these more frequent patients are the visual hallucinations, followed by the auditory and olfactory hallucinations.

As for verbal aggression, it is present on average in $24 \%$ (from $11 \%$ to $51 \%$ ) of dementia patients, usually accompanying the more advanced stages of the disease. Physical aggression is also a frequent phenomenon, observed on average in $14 \%$ of these patients (from $1 \%$ to $56 \%$ ), being more common in institutionalized individuals, emphasize Forlenza \& Diniz. ${ }^{4}$

Cohen-Mansfield, Marx \& Rosenthal ${ }^{6}$ emphasize that physical agitation in dementia patients can be described by the presence of inappropriate motor and verbal activities that are not explained by the patient's need but may also be associated with mental confusion (including several different symptoms, such as unspecific physical restlessness, non-cooperation, negativism, or repetitive verbal behaviors (repetition of sentences or incessant production of complaints and solicitations) and motors (stereotypes, usage behaviors, perambulation). As Ballard, Waite \& Birks ${ }^{7}$ point out, aggressiveness, agitation or psychosis occur in the majority of people with dementia at some point in the disease.

For the American Psychiatric Association in its Practice Guideline
Volume 3 Issue I - 2018

\author{
César Augusto Trinta Weber,' Marcos Paulo \\ Betinarti ${ }^{2}$ \\ 'Department of Neurosciences, Faculty of Medicine of Ribeirão \\ Preto, University of São Paulo, Brazil \\ ${ }^{2}$ Psychiatrist and Psychotherapist, Spiritist Hospital of Porto \\ Alegre, Brazil
}

Correspondence: Dr. César Augusto Trinta Weber, Researcher of the Program of Assistance, Teaching and Research in Stress, Trauma and Affective Diseases-EsTra DA, of the Department of Neurosciences, Faculty of Medicine of Ribeirão César Augusto Trinta Weber, University of São Paulo, Brazil, Tel +555। 999179797, Email trintaweber@hotmail.com

Received: January 30, 20I8 | Published: February 14, 2018

on the Use of Antipsychotics to Treat Agitation or Psychosis in Patients with Dementia ${ }^{8}$ dementia is associated with a considerable burden of public health care that is growing rapidly as population ages. In addition to cognitive deficits, individuals with dementia often receive clinical attention due to symptoms of a behavioral disorder (eg, irritability, agitation, aggression) or psychosis. The burden for caregivers is substantial and increases when dementia is associated with behavioral and psychological symptoms, and particularly with agitation or aggression. The treatment of psychotic symptoms and restlessness in individuals with dementia frequently involved the use of antipsychotic medications. In recent years, the risks associated with the use of these agents in the older adult population have become apparent. There was an increasing need to develop guidelines for the proper use of antipsychotic medications in dementia.

Without neglect, it is worth emphasizing that behavioral changes in the elderly can be a burden of stress for their caregivers, in addition to consubstantiating, in fact, contextualized and situational conditions in situations that may put the patient at risk

It is important to emphasize that, in spite of increasing the risk of mortality, in the name of caution and prudence the stress level must be weighed and the unmedicated patient presents risks to himself or others.

Finally, the decision to use an antipsychotic medication to treat behavioral changes in patients with major neurocognitive disorder (dementia) requires that the attending physician conduct a careful assessment of the risk analysis versus potential benefits.

\section{Acknowledgements}

None.

\section{Conflict of interest}

The authors declare no conflict of interest. 


\section{References}

1. Maust DT, Kim HM, Seyfried LS, et al. Antipsychotics, Other Psychotropics, and the Risk of Death in Patients With Dementia Number Needed to Harm. JAMA Psychiatry. 2015;72(5):438-445.

2. Donaldson C, Tarrier N, Burns A. Determinants of carer stress in Alzheimer's disease. Int J Geriatr Psychiatry. 1998;13(4):248-256.

3. Ballard CG, Eastwood C, Gahir M, et al. A follow-up study of depression in the carers of dementia sufferers. BMJ. 1996;312(7036):947.

4. Forlenza OV, Cretaz E, Diniz BSO. O uso de antipsicóticos em pacientes com diagnóstico de demência. Rev Bras Psiquiatr. 2008;30(3):265-270.
5. Sultzer DL. Psychosis and antipsychotic medications in Alzheimer's disease: clinical management and research perspectives. Dement Geriatr Cogn Disord. 2004;17(1-2):78-90.

6. Cohen-Mansfield J, Marx M, Rosenthal AS. A description of agitation in a nursing home. J Gerontol. 1989;44(3):M77-M84.

7. Ballard CG, Waite J, Birks J. Atypical antipsychotics for aggression and psychosis in Alzheimer's disease. Cochrane Database of Systematic Reviews. 2006;25(1):CD003476.

8. American Psychiatric Association. Practice Guideline on the use of Antipsychotics to Treat Agitation or Psychosis in Patients with Dementia. Washington, USA; 2016. 